\title{
Optimization of lead adsorption of mordenite by response surface methodology: characterization and modification
}

\author{
Havva Turkyilmaz ${ }^{1 \dagger}$, Tolga Kartal ${ }^{1 \dagger}$ and Sibel Yigitarslan Yildiz $2^{2^{*}}$
}

\begin{abstract}
Background: In order to remove heavy metals, water treatment by adsorption of zeolite is gaining momentum due to low cost and good performance. In this research, the natural mordenite was used as an adsorbent to remove lead ions in an aqueous solution.

Methods: The effects of adsorption temperature, time and initial concentration of lead on the adsorption yield were investigated. Response surface methodology based on Box-Behnken design was applied for optimization. Adsorption data were analyzed by isotherm models. The process was investigated by batch experiments; kinetic and thermodynamic studies were carried out. Adsorption yields of natural and hexadecyltrimethylammoniumbromide-modified mordenite were compared.

Results: The optimum conditions of maximum adsorption (nearly 84 percent) were found as follows: adsorption time of $85-90 \mathrm{~min}$, adsorption temperature of $50^{\circ} \mathrm{C}$, and initial lead concentration of $10 \mathrm{mg} / \mathrm{L}$. At the same optimum conditions, modification of mordenite produced 97 percent adsorption yield. The most appropriate isotherm for the process was the Freundlich. Adsorption rate was found as 4.4. Thermodynamic calculations showed that the adsorption was a spontaneous and an exothermic process.

Conclusions: Quadratic model and reduced cubic model were developed to correlate the variables with the adsorption yield of mordenite. From the analysis of variance, the most influential factor was identified as initial lead concentration. At the optimum conditions modification increased the adsorption yield up to nearly 100 percent. Mordenite was found an applicable adsorbent for lead ions especially in dilute solutions and may also be applicable in more concentrated ones with lower yields.
\end{abstract}

Keywords: Risk, Environment, Hazard, Lead, Adsorption

\section{Background}

Heavy metals are defined as those having higher density than $5000 \mathrm{~g} / \mathrm{L}$ [1]. When their concentrations reach a certain level, they cause serious damage to the environment, animals and public health. Lead is one such extremely toxic element even at low concentrations that can damage to the nervous system, gastrointestinal tract, reproductive system, liver and brain [2,3]. Major industries of lead pollution are mining, paint, chemical, textile etc. [4]. Lead discharge from them to the atmosphere is

\footnotetext{
* Correspondence: yildizsibel@sdu.edu.tr

${ }^{\dagger}$ Equal contributors

${ }^{2}$ Chemical Engineering Department, Suleyman Demirel University, Cunur, Isparta, Turkey

Full list of author information is available at the end of the article
}

approximately 2000 kilotons/year; thus lead pollution is serious environmental problems of worldwide. There are conventional methods for removing lead from aqueous solution such as reverse osmosis, ion exchange, electrochemical treatment, solvent extraction, chemical precipitation, adsorption and biosorption [5,6]. Among those, adsorption is a simple process with low cost and good performance [7]. High exchange capacity, high specific surface area and low cost make natural zeolites good adsorbents $[8,9]$. Their adsorption capacity can also be further increased by modification with various agents, such as CTAB (cetyltrimethylammoniumbromide) and HDTMA (hexadecyltrimethylammonium-bromide) [9]. A special type of zeolite, mordenite is abundant in nature. Comparing

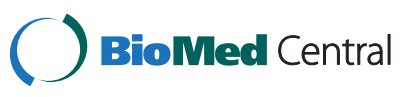


to other zeolites, it has rather low $\mathrm{Si} / \mathrm{Al}$ ratio (5:1) which may render the adsorption of lead [10]. Removal of heavy metal ions by using mordenite is very rare [11-14]. None of the studies investigated the effect of modification of mordenite on adsorption yield. Above studies have shown that lead removal by mordenite is strongly dependent upon the initial concentration of lead and adsorption conditions. In assessing the effect (single effect and interactive effects) of variables on quality attributes an adequate experimental design is required. Response Surface Methodology (RSM) has an important application for analyzing effects of several independent variables and also interactive effects among the variables on the response. Nevertheless, no study has been found in the literature for optimization of adsorption of lead ions by mordenite, neither modified nor unmodified. The objective of the present research was to optimize the adsorption conditions of lead ions by mordenite. It was thought that the level of adsorption may be further increased by modification of mordenite with HDTMA. The effects of variables including initial lead concentration, adsorption time and temperature on adsorption yield were investigated by three-variable-three-level Box-Behnken Design (BBD). Emprical model correlating response to the three variables was then developed. Langmuir and Freundlich isotherm models were investigated in terms of their appropriateness and fractional-life method was used to determine kinetic parameters. The thermodynamic parameters of the process were also calculated.

\section{Methods}

\section{Chemicals and reagents}

Mordenite, a type of zeolite, was selected for having high ion-exchange capacity, high surface area and low Si/Al ratio. Mordenite, analytical grades of lead nitrate $(\mathrm{Pb}$ $\left.\left(\mathrm{NO}_{3}\right)_{2}\right)$ and HDTMA were purchased from Sigma and used without further purification. Three stock lead nitrate solutions $(10 \mathrm{mg} / \mathrm{L}, 1005 \mathrm{mg} / \mathrm{L}$, and $2000 \mathrm{mg} / \mathrm{L})$ were prepared and used in adsorption studies as working solutions.

\section{Analysis and measurements}

Elemental analysis of natural mordenite was determined by Perkin-Elmer (2400 series) Elemental Analyzer. The surface area of mordenite was determined by BET analysis of Micromeritics (Gemini 2360). The concentrations of residual lead(II) ions in the supernatant solutions were determined using ICP-OES (Perkin-Elmer Optima 5300 DV) measurements.

\section{Design of experiments, model fitting and statistical analysis}

The optimum condition for the adsorption of lead by mordenite was determined by means of BBD and RSM. RSM is a collection of statistical and mathematical techniques useful for evaluation of relationship existing between a number of controlled experimental factors and measured responses according to one or more selected criteria $[15,16]$. Optimization studies were carried out by studying the effect of three variables including initial lead ion concentration, adsorption temperature and time. The chosen independent variables in this study were coded according to Eq. (1):

$$
X_{i}=\frac{X_{i}-X_{0}}{\Delta X}
$$

where $x_{i}$ is the dimensionless coded value of the ith independent variable, $x_{0}$ is the value of $x_{i}$ at the center point and $\Delta \mathrm{x}$ is the step change value. The behavior of the system is explained by the following empirical second-order polynomial model (Eq. 2):

$$
\begin{aligned}
Y= & \beta_{0}+\sum_{i=1}^{k} \beta_{i} x_{i}+\sum_{i=1}^{k} \beta_{i i} x_{i}^{2} \\
& +\sum_{i=1}^{k-1} \sum_{j=2}^{k} \beta_{i j} x_{i} x_{j}+\varepsilon
\end{aligned}
$$

where $\mathrm{Y}$ is the predicted response, $x_{i}, x_{j}, \ldots, x_{k}$ are the input variables, which affect the response $\mathrm{Y}, x_{i}^{2}, x_{j}^{2}, \ldots, x_{k}^{2}$ are the square effects, $\beta_{0}$ is the intercept term, $x_{i} x_{j}, x_{j} x_{k}$ and $x_{i} x_{k}$ are the interaction effects, $\beta_{\mathrm{i}}(\mathrm{i}=1,2, \ldots, \mathrm{k})$ is the linear effect, $\beta_{\mathrm{ii}}(\mathrm{i}=1,2, \ldots, \mathrm{k})$ is the squared effect, $\beta_{\mathrm{ij}}(\mathrm{j}=1,2, \ldots, \mathrm{k})$ is the interaction effect and $\varepsilon$ is a random error [17-19].

The Design-Expert 8.0 (Stat-Ease Inc., Minneapolis $\mathrm{MN}$, USA) software was used for regression and graphical analysis of the experimental data to fit the equations developed and for evaluation of their statistical significance. BBD is frequently used under RSM design. The study carried out involved the employment of BBD to optimize the adsorption process due to its suitability to fit quadratic surface that usually works well for process optimization. Design of 15 experiments consisting of three replicates at the central points was employed to the second-order polynomial model. The optimum values of the selected variables were obtained by solving the regression equation at desired values of the process responses as the optimization criteria. Each of the parameters was coded at three levels: $-1,0$, and +1 . The range of variables was decided on the basis of preexperimental values. The range and level of the variable in coded units for RSM studies were given in Table 1.

Each experiment was repeated three times (average values were used in optimization) and the experimental sequence was randomized in order to minimize the effects of the uncontrolled factors.

\section{Lead adsorption studies}

Fifteen batch adsorption experiments designed by RSM were conducted with $0.50 \mathrm{~g}$ of mordenite (dried in an oven at $60^{\circ} \mathrm{C}$ for $24 \mathrm{~h}$ ) at agitation speed of $200 \mathrm{rpm}$ and 
Table 1 Experimental ranges and levels of the independent variables

\begin{tabular}{lccc}
\hline Independent variables & \multicolumn{3}{c}{ Range and level } \\
\hline & -1 & 0 & +1 \\
Adsorption time, $\min \left(X_{1}\right)$ & 30 & 75 & 120 \\
Adsorption temperature, ${ }^{\circ} \mathrm{C}\left(\mathrm{X}_{2}\right)$ & 20 & 35 & 50 \\
Initial lead ion concentration, $\mathrm{mg} / \mathrm{L}\left(\mathrm{X}_{3}\right)$ & 10 & 1005 & 2000 \\
\hline
\end{tabular}

the initial $\mathrm{pH}$ of working solution. Each experiment was carried out in Erlenmeyer flasks containing $100 \mathrm{ml}$ lead (II) solution at determined temperature in an isothermal shaker. Samples were withdrawn at the end of the determined contact time and filtered through $0.25 \mu \mathrm{m}$ filters. Filtered samples were analyzed for residual lead ion concentration. Natural mordenite particles were modified according to the reaction with $100 \mathrm{ml}$ of HDTMA solution $(0.05 \mathrm{M})$ at $30^{\circ} \mathrm{C}$ in a reactor containing $5 \mathrm{~g}$ mordenite particles and magnetically stirred for $3 \mathrm{~h}$. At the end of the reaction, zeolite particles were separated by filtration, washed several times with distilled water and dried in an oven at $60^{\circ} \mathrm{C}$ for $24 \mathrm{~h}$. Same adsorption procedure was applied to HDTMA-mordenite except that the conditions chosen as the optimum of unmodified one. Metal removal by mordenite was determined according to Eq. (3):

$$
R=\frac{P_{0}-P_{e}}{P_{0}} \times 100
$$

where $\mathrm{R}$ is the percentage of lead adsorbed by adsorbent, $\mathrm{P}_{0}$ is the initial concentration of metal ion in $\mathrm{mg} / \mathrm{L}$ and $\mathrm{P}_{\mathrm{e}}$ is the final concentration of metal ion in $\mathrm{mg} / \mathrm{L}$.

\section{Adsorption isotherms}

In order to diagnose the nature of adsorption (homogeneous or heterogeneous) onto the mordenite the equilibrium adsorption isotherms are required. Two theoretical isotherm models, namely Langmuir (applicable to homogeneous adsorption) and Freundlich (applicable to heterogeneous adsorption) isotherms, were used to fit the adsorption data obtained at $35^{\circ} \mathrm{C}$. For Langmuir isotherm [20]:

$$
\frac{C_{e}}{Q}=\frac{1}{Q_{0} b}+\frac{C_{e}}{Q_{0}}
$$

where $\mathrm{C}_{\mathrm{e}}$ is the equilibrium concentration $(\mathrm{mg} / \mathrm{L}), \mathrm{Q}$ is the amount of metal adsorbed $(\mathrm{mg} / \mathrm{g})$, $\mathrm{b}$ is sorption constant $(\mathrm{L} / \mathrm{mg})\left(\right.$ at $\left.35^{\circ} \mathrm{C}\right)$ related to the energy of sorption, and $\mathrm{Q}_{0}$ is the maximum sorption capacity $(\mathrm{mg} / \mathrm{g})$. For Freundlich isotherm [20]:

$$
Q_{e}=K_{F} C_{e}^{1 / n}
$$

where $\mathrm{Q}_{\mathrm{e}}$ is the amount of metal adsorbed at the equilibrium $(\mathrm{mg} / \mathrm{g}), \mathrm{K}_{\mathrm{F}}\left((\mathrm{mg} / \mathrm{g})(\mathrm{L} / \mathrm{mg})^{1 / \mathrm{n}}\right)$ and $\mathrm{n}$ (dimensionless) are Freundlich constants related to the adsorption capacity and adsorption intensity, respectively. The regression analysis and calculation of constants of Eq. (4) and (5) were achieved by using the solver add-in function of MS Excel.

\section{Adsorption kinetics}

The adsorption data obtained with $1005 \mathrm{mg} / \mathrm{L}$ initial lead ion concentration were then fitted to the fractionallife method [21]:

$$
t_{F}=\frac{F^{1-n}-1}{k(n-1)} C_{A 0}^{1-n}
$$

where $F$ is the fractional value $\left(C_{A} / C_{A 0}\right)$ in time $t_{F} ; n$ the reaction order; $k$ reaction rate constant; and $\mathrm{C}_{\mathrm{A}}$ the concentration of reactant $\mathrm{A}(\mathrm{mg} / \mathrm{L})$ at time $\mathrm{t}(\mathrm{min})$. Kinetic parameters of adsorption were determined by plotting $\log t_{\mathrm{F}}$ versus $\log \mathrm{C}_{\mathrm{A} 0}$ and using MS Excel.

\section{Adsorption thermodynamics}

Since temperature is an important parameter effecting both adsorption capacity of mordenite and transport/ kinetic process of lead adsorption, the thermodynamic parameters of the process such as enthalpy $\left(\Delta \mathrm{H}^{\circ}\right)$, entropy $\left(\Delta \mathrm{S}^{\circ}\right)$, and free energy $\left(\Delta \mathrm{G}^{\circ}\right)$ of lead adsorption on mordenite were calculated by using following thermodynamic relations $[19,22]$ :

$$
\begin{aligned}
& \Delta G^{0}=-R T \operatorname{In} K_{c}^{0} \\
& \Delta G^{\circ}=\Delta \mathrm{H}^{\circ}-\mathrm{T} \Delta \mathrm{S}^{\circ}
\end{aligned}
$$

Combining these to relations:

$$
\operatorname{In} K_{c}^{0}=\frac{\Delta S^{0}-\Delta H^{0}}{R} * \frac{1}{T}
$$

where $\mathrm{R}$ is universal gas constant $\left(8.314 \mathrm{Jmol}^{-1} \mathrm{~K}^{-1}\right)$, $\mathrm{T}$ is the temperature $(\mathrm{K})$ and $\mathrm{K}_{\mathrm{c}}$ is the equilibrium constant at that temperature calculated by the equation:

$$
K_{c}=\frac{C_{a}}{C_{e}}
$$

where $C_{a}$ is the concentration of the adsorbed material $(\mathrm{mg} / \mathrm{L})$, and $\mathrm{C}_{\mathrm{e}}$ is the concentration of remaining material in solution $(\mathrm{mg} / \mathrm{L})$.

\section{Results}

\section{Properties of natural and modified mordenite}

Natural mordenite has a purity of 99.8 percent with impurity of magnesium. According to the chemical composition of the zeolite, the chemical formula was determined as $\mathrm{K}_{2.87} \mathrm{Ca}_{1.43} \mathrm{Na}_{1.27} \mathrm{Al}_{7.98} \mathrm{Si}_{40} \mathrm{O}_{88} \cdot 25 \mathrm{H}_{2} \mathrm{O}$. This result showed that the major components of mordenite were silica and alumina and the ratio of $\mathrm{Si} / \mathrm{Al}$ was 5.215. The surface area of the mordenite was determined as $53 \mathrm{~m}^{2} / \mathrm{g}$ with BET 
analysis. HDTMA-modification was corrected with the elemental analysis [23]. The ratio of $\mathrm{C} / \mathrm{N}$ for HDTMAmordenite showed that 4.15 percent of modifying agent was transferred onto the surface of the zeolite.

\section{Regression model and optimization}

The coded and actual values of the test variables and lead removal percentage were summarized in Table 2. Predicted values for yield by using quadratic model and reduced cubic model were summarized in Tables 3 and 4 , respectively. The statistical significance of the quadratic and reduced cubic models was evaluated by analysis of variance (ANOVA) as presented in Table 5 and 6 , respectively.

According to the statistical analysis, the empirical relationship in coded units obtained by RSM was as follows:

$$
\begin{aligned}
Y= & 48.42+4.20 x_{1}+10.71 x_{2}-8.64 x_{3} \\
& +0.28 x_{1} x_{2}-3.60 x_{1} x_{3}-8.44 x_{2} x_{3}-1.02 x_{1}^{2}-1.26 x_{2}^{2} \\
& +8.55 x_{3}^{2}-8.29 x_{1}^{2} x_{2}+0.99 x_{1}^{2} x_{3}-3.11 x_{1} x_{2}^{2}
\end{aligned}
$$

where $\mathrm{Y}$ is lead ion removal (response) in percentage, $x_{1}, x_{2}$ and $x_{3}$ are the coded values of variables; adsorption time in min $\left(x_{1}\right)$, adsorption temperature in ${ }^{\circ} \mathrm{C}\left(x_{2}\right)$, and initial lead ion concentration in $\mathrm{mg} / \mathrm{L}\left(x_{3}\right)$.

The results of regression analysis on reduced cubic model are given in Table 7. The significant of each coefficient was determined by F-values and p-values (Table 7). The larger the magnitude of the F-values and the smaller p-values, the more significant is the corresponding coefficients. Values of

Table 2 Experimental design matrix based on Box-

Behnken and results

\begin{tabular}{lccccccc}
\hline $\begin{array}{l}\text { Run } \\
\text { no }\end{array}$ & \multicolumn{5}{c}{ Independent variables } & \multirow{2}{*}{$\begin{array}{c}\text { Observed } \\
\text { values }\end{array}$} \\
\cline { 2 - 6 } 1 & -1 & 0030 & -1 & 30 & 35 & 10 & 55.800 \\
2 & 0 & +1 & -1 & 75 & 50 & 10 & 83.500 \\
3 & +1 & 0 & -1 & 120 & 35 & 10 & 71.400 \\
4 & 0 & +1 & +1 & 75 & 50 & 2000 & 49.350 \\
5 & 0 & 0 & 0 & 75 & 35 & 1005 & 48.498 \\
6 & -1 & +1 & 0 & 30 & 50 & 1005 & 47.190 \\
7 & 0 & 0 & 0 & 75 & 35 & 1005 & 48.373 \\
8 & +1 & 0 & +1 & 120 & 35 & 2000 & 48.900 \\
9 & +1 & -1 & 0 & 120 & 20 & 1005 & 44.530 \\
10 & 0 & 0 & 0 & 75 & 35 & 1005 & 48.385 \\
11 & 0 & -1 & -1 & 75 & 20 & 10 & 45.200 \\
12 & +1 & +1 & 0 & 120 & 50 & 1005 & 49.930 \\
13 & -1 & -1 & 0 & 30 & 20 & 1005 & 42.915 \\
14 & -1 & 0 & +1 & 30 & 35 & 2000 & 47.700 \\
15 & 0 & -1 & +1 & 75 & 20 & 2000 & 44.800 \\
\hline
\end{tabular}

Table 3 Observed and predicted values for the quadratic model

\begin{tabular}{lccc}
\hline Run no & Observed values & Predicted value & Residual \\
\hline 1 & 55.800 & 57.850 & -2.05 \\
2 & 83.500 & 78.860 & 4.64 \\
3 & 71.400 & 70.340 & 1.06 \\
4 & 49.350 & 45.700 & 3.65 \\
5 & 48.498 & 48.420 & 0.079 \\
6 & 47.190 & 49.780 & -2.59 \\
7 & 48.373 & 48.420 & -0.046 \\
8 & 48.900 & 46.850 & 2.05 \\
9 & 44.530 & 41.940 & 2.59 \\
10 & 48.385 & 48.420 & -0.034 \\
11 & 45.200 & 48.850 & -3.65 \\
12 & 49.930 & 55.630 & -5.70 \\
13 & 42.915 & 37.210 & 5.70 \\
14 & 47.700 & 48.760 & -1.06 \\
15 & 44.800 & 49.440 & -4.64 \\
\hline
\end{tabular}

"prob > F" less than 0.0500 also indicated high significant regression at 95 percent confidence level. According to the F- and p-values, adsorption temperature and initial ion concentration were found more effective on the adsorption process. Figure 1 shows the simultaneous effects of adsorption temperature (a) and initial lead ion concentration (b) on lead removal efficiency.

In the numerical optimization desirability function was used. In order to determine the usability of mordenite in low and high concentrated lead solutions, time and

Table 4 Observed and predicted values for the reduced cubic model

\begin{tabular}{lccc}
\hline Run no & Observed values & Predicted value & Residual \\
\hline 1 & 55.800 & 55.800 & 0.000 \\
2 & 83.500 & 83.500 & 0.000 \\
3 & 71.400 & 71.400 & 0.000 \\
4 & 49.350 & 49.350 & 0.000 \\
5 & 48.498 & 48.420 & 0.078 \\
6 & 47.190 & 47.190 & 0.000 \\
7 & 48.373 & 48.420 & -0.047 \\
8 & 48.900 & 48.900 & 0.000 \\
9 & 44.530 & 44.530 & 0.000 \\
10 & 48.385 & 48.420 & -0.035 \\
11 & 45.200 & 45.200 & 0.000 \\
12 & 49.930 & 49.930 & 0.000 \\
13 & 42.915 & 42.920 & 0.005 \\
14 & 47.700 & 47.700 & 0.000 \\
15 & 44.800 & 44.800 & 0.000 \\
\hline
\end{tabular}


Table 5 Analysis of variance (ANOVA) for the quadratic model

\begin{tabular}{llllll}
\hline $\begin{array}{l}\text { Source of } \\
\text { variations }\end{array}$ & $\begin{array}{l}\text { Degrees of } \\
\text { freedom }\end{array}$ & $\begin{array}{l}\text { Sum of } \\
\text { squares }\end{array}$ & $\begin{array}{l}\text { Mean } \\
\text { square }\end{array}$ & F-value & Probability (p) \\
\hline Regression & 9 & 1560.78 & 173.42 & 5.46 & 0.0381 \\
$\begin{array}{l}\text { Main } \\
\text { effects }\end{array}$ & 3 & 931.37 & 931.37 & 29.31 & 0.2419 \\
$\begin{array}{l}\text { Square } \\
\text { effects }\end{array}$ & 3 & 279.68 & 279.68 & 8.80 & 0.7422 \\
$\begin{array}{l}\text { Interaction } \\
\text { effects }\end{array}$ & 3 & 336.93 & 336.93 & 10.60 & 0.9244 \\
Residual & 5 & 158.89 & 31.78 & & \\
Total & 14 & 1719.67 & & & \\
\hline$R^{2} ; 0076,9 d j u$ & & & & \\
\hline
\end{tabular}

$\mathrm{R}^{2} ; 0.9076$, adjusted $\mathrm{R}^{2} ; 0.7413$, predicted $\mathrm{R}^{2} ;-0.4783$, lack of fit; 11134.81 , CV; 10.89.

temperature were set within range, and level of lead removal was set at maximum in each criteria (Table 8). Initial lead ion concentration was set as different targets for maximum desirability. By seeking from several starting points for each criteria, the best local maximums for each were obtained and summarized in Table 8.

\section{Characterization of adsorption}

In the present study, Langmuir and Freundlich isotherm models [20] were applied to the experimental data to determine the type of adsorption (homogeneous, heterogeneous). The adsorption constants of each isotherm were summarized in Table 9. According to those, the value of $\mathrm{R}^{2}$ so lower than 1 , demonstrating that Langmuir isotherm is not applicable for describing the adsorption. The experimental data fitted well to Freundlich Model $\left(R^{2}=0.993\right)$ which shows that mordenite has a form of surface heterogeneity [20].

The adsorption kinetics was determined by fractionallife method chosing the fractional value of 0.8 [21]. The reaction rate was 4.39 at $0^{\circ} \mathrm{C}$ for $1005 \mathrm{mg} / \mathrm{L}$ of initial

Table 6 Analysis of variance (ANOVA) for the reduced cubic model

\begin{tabular}{llllll}
\hline $\begin{array}{l}\text { Source of } \\
\text { variations }\end{array}$ & $\begin{array}{l}\text { Degrees of } \\
\text { freedom }\end{array}$ & $\begin{array}{l}\text { Sum of } \\
\text { squares }\end{array}$ & $\begin{array}{l}\text { Mean } \\
\text { square }\end{array}$ & F-value & Probability (p) \\
\hline Regression & 12 & 1719.66 & 143.30 & 30129.29 & $<0.0001$ \\
$\begin{array}{l}\text { Main } \\
\text { effects }\end{array}$ & 3 & 828.02 & 828.02 & 174087.1 & $<0.0001$ \\
$\begin{array}{l}\text { Square } \\
\text { effects }\end{array}$ & 3 & 279.68 & 279.68 & 58801.17 & 0.0012 \\
$\begin{array}{l}\text { Interaction } \\
\text { effects }\end{array}$ & 3 & 336.93 & 336.93 & 70836.5 & 0.0147 \\
$\begin{array}{l}\text { Added } \\
\text { terms }\end{array}$ & 3 & 158.88 & 158.88 & 33404.44 & 0.0024 \\
Total & 14 & 1719.67 & & & \\
\hline
\end{tabular}

$\mathrm{R}^{2} ; 1.000$, adjusted $\mathrm{R}^{2} ; 1.000, \mathrm{CV} ; 0.13$.
Table 7 Regression analysis for the reduced cubic model

\begin{tabular}{lcccc}
\hline Model term & $\begin{array}{c}\text { Coefficient } \\
\text { estimate }\end{array}$ & Standart error & F-Value & p-Value \\
\hline Intercept & +48.42 & 0.04 & 30129.29 & $<0.0001$ \\
$x_{1}$ & +4.20 & 0.034 & 14834.96 & $<0.0001$ \\
$x_{2}$ & +10.71 & 0.034 & 96509.35 & $<0.0001$ \\
$x_{3}$ & -8.64 & 0.034 & 62742.79 & $<0.0001$ \\
$x_{1} x_{2}$ & +0.28 & 0.034 & 66.52 & 0.0147 \\
$x_{1} x_{3}$ & -3.60 & 0.034 & 10899.15 & $<0.0001$ \\
$x_{2} x_{3}$ & -8.44 & 0.034 & 59870.83 & $<0.0001$ \\
$x_{1}^{2}$ & -1.02 & 0.036 & 807.59 & 0.0012 \\
$x_{2}^{2}$ & -1.26 & 0.036 & 1227.48 & 0.0008 \\
$x_{3}^{2}$ & +8.55 & 0.036 & 56766.10 & $<0.0001$ \\
$x_{1}^{2} x_{2}$ & -8.29 & 0.049 & 28924.08 & $<0.0001$ \\
$x_{1}^{2} x_{3}$ & +0.99 & 0.049 & 410.05 & 0.0024 \\
$x_{1} x_{2}^{2}$ & -3.11 & 0.049 & 4070.31 & 0.0002 \\
\hline
\end{tabular}

lead concentration (Figure 2) and the rate constant was calculated as $3.75 .10^{-14} \mathrm{~min}^{-1}(\mathrm{mg} / \mathrm{L})^{-3.39}$.

The thermodymanics of adsorption of lead on mordenite was studied at temperatures of 20,35 , and $50^{\circ} \mathrm{C}$. The change in Gibbs free energy $\left(\Delta G^{\circ}\right)$, enthalpy $\left(\Delta H^{\circ}\right)$, and entropy $\left(\Delta \mathrm{S}^{\circ}\right)$ values were obtained by using Eq. (9) and the results were summarized in Table 10.

\section{Discussion}

In order to develop an equation describing the relation between the adsorption yield and three adsorption variables shown in Table 2, a BBD was conducted. Quadratic model and reduced cubic model were developed to correlate the variables to the response. Predicted values for yield by using reduced cubic model (Table 4) were closer to observed values than those by using quadratic model (Table 3). In quadratic model (Table 5), F-value of the model 5.46 implied that the model was statistically significant. There was only a 3.81 percent chance that a model F-value this large could occur due to noise. The fit of the model was checked by the determination coefficient $\left(R^{2}\right)$. In this case, the value of the determination coefficient $\left(R^{2}=0.9076\right)$ indicated that 9.24 percent of the total variable was not explained by the model. The value of adjusted determination coefficient (adjusted $\left.R^{2}=0.7413\right)$ was low and it was not in reasonable agreement with the adjusted $R^{2}$. Negative predicted $R^{2}$ implied that the overall mean was a better predictor of the response than the current model. Significant lacks of fit and high value of the coefficient of variation were found. Probability values (greater than 0.1000 ) indicated that some of the model terms are not significant. But, reduced cubic model (Table 6) produced the closest predicted values, predicted $R^{2}$ and adjusted $R^{2}$ equal to 1 , 


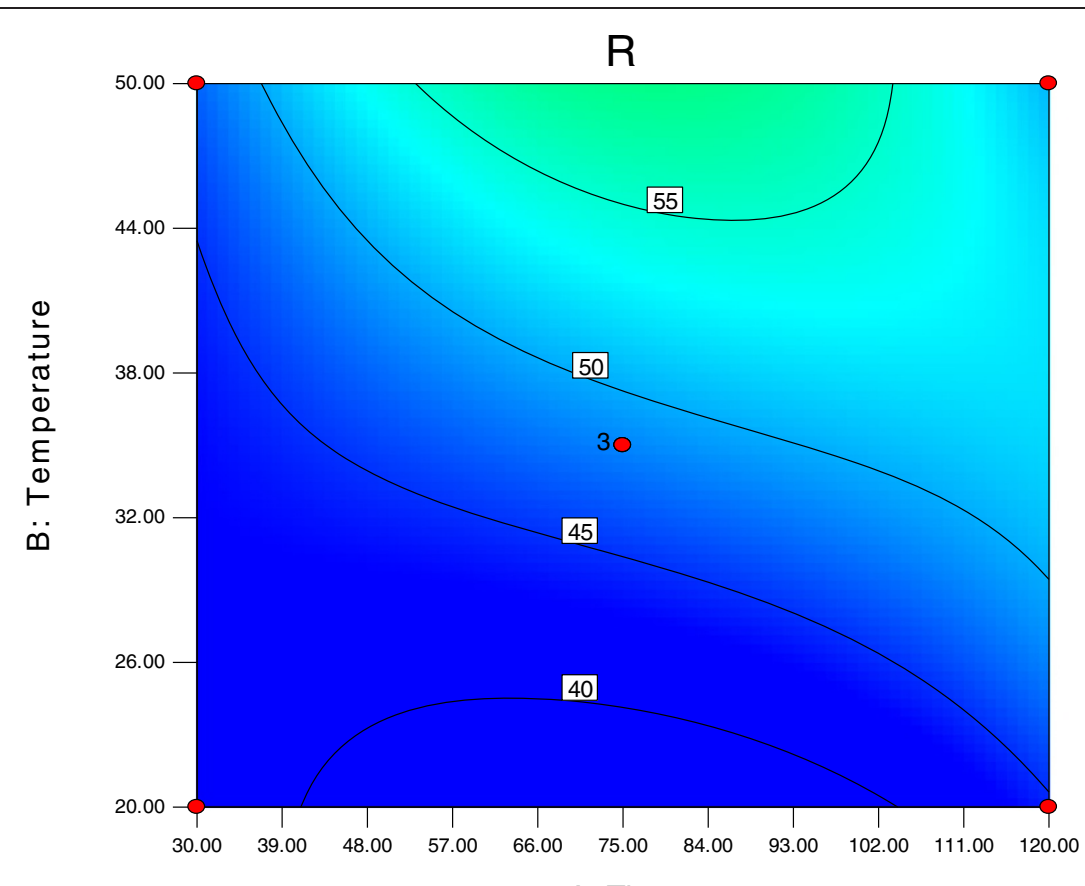

A: Time

(a)

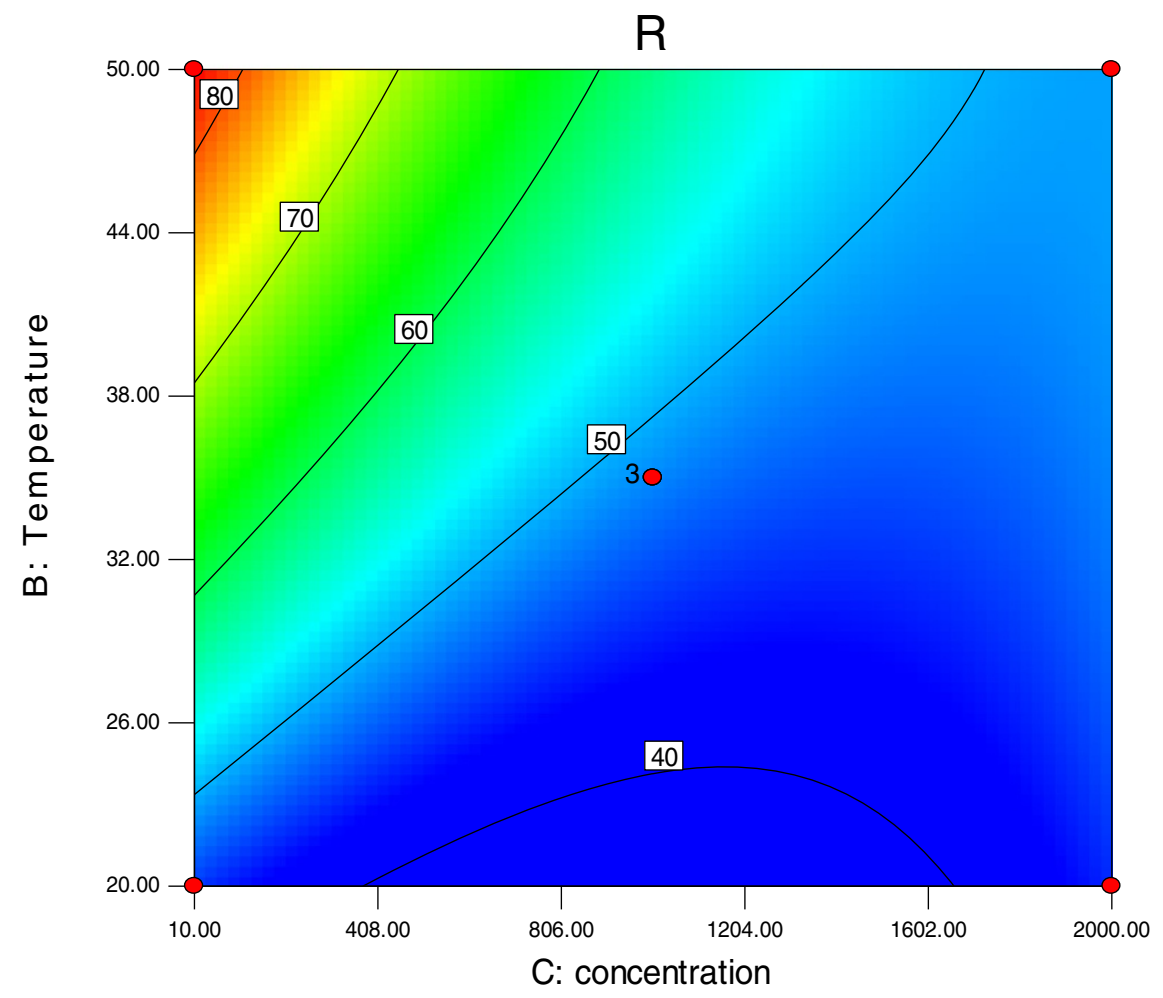

(b)

Figure 1 Contour plots for the effect of $(\mathrm{a})$ adsorption temperature $\left({ }^{\circ} \mathrm{C}\right)$ and adsorption time $(\mathrm{min}) ;(\mathrm{b})$ adsorption temperature $\left({ }^{\circ} \mathrm{C}\right)$ and initial lead ion concentration $(\mathrm{mg} / \mathrm{L}$ ) on the lead removal (black-and-white form). 
Table 8 Numerical optimization of the model obtained by desirability function

\begin{tabular}{llll}
\hline Criteria & Solution & Desirability \\
\hline $1 \quad$ Adsorption time: in range & 89.47 & 1.000 \\
Adsorption temperature: in range & 49.68 & \\
Initial lead concentration: target $=10$ & 10.00 & \\
Lead removal: maximize & 83.7369 & \\
2. & 85.29 & 0.968 \\
Adsorption time: in range & 50.00 & \\
Adsorption temperature: in range & 100.00 & \\
Initial lead concentration: target $=100$ & 81.0066 & \\
Lead removal: maximize & 81.83 & 0.602 \\
Adsorption time: in range & 50.00 & \\
Adsorption temperature: in range & 799.10 & \\
Initial lead concentration: target $=1000$ & 61.8751 & \\
Lead removal: maximize & 82.66 & 0.425 \\
Adsorption time: in range & 50.00 & \\
Adsorption temperature: in range & 828.11 & \\
Initial lead concentration: target = 2000 & 61.2467 & \\
Lead removal: maximize & &
\end{tabular}

no lack of fit and low coefficient of variance. The model F-value implied that the model was significant, and there was only a 0.01 percent chance occurs due to noise. Thus, as a result of the statistical analysis, reduced cubic model was found satisfactory for describing the process and useful for developing empirical relation.

Lead removal showed to be very sensitive to changes in the temperature both in dilute and in concentrated solutions. The removal capacity of mordenite was sharply increased when the adsorption temperature increased from 20 to $50^{\circ} \mathrm{C}$ in dilute solutions; as it was also reported by Wang [14] (from 20 to $40^{\circ} \mathrm{C}$; in a solution of $40 \mathrm{mg}$ lead/L). No comparison can be made with the research by Dai et al. [13] since the temperature set constant at $25^{\circ} \mathrm{C}$. For moderately concentrated solutions $(1005 \mathrm{mg} / \mathrm{L})$ this increase in yield was only 5 percent. The increase in yield due to increase in adsorption temperature in diluted solutions was more dominated than one in concentrated solutions.

Initial lead ion concentration was another parameter that has high effect on the response. As can be seen on Figure 1, the concentration of the aqueous solution increases the removal of lead decreases. About 84 percent

Table 9 Isotherm model constants for the adsorption of lead on mordenite $\left(\mathrm{T}: 35^{\circ} \mathrm{C}\right.$, sorbent dosage: $0.5 \mathrm{~g}$, initial lead concentration: $10-2000 \mathrm{mg} / \mathrm{L}$ )

\begin{tabular}{cccccc}
\hline \multicolumn{3}{c}{ Langmuir model } & \multicolumn{3}{c}{ Freundlich model } \\
\hline $\mathrm{Q}_{0}(\mathrm{mg} / \mathrm{g})$ & $\mathrm{b}(\mathrm{L} / \mathrm{mg})$ & $\mathrm{R}^{2}$ & $1 / \mathrm{n}$ & $\mathrm{K}_{\mathrm{F}}$ & $\mathrm{R}^{2}$ \\
4.387 & 0.0006 & 0.571 & 0.876 & 0.0041 & 0.993 \\
\hline
\end{tabular}

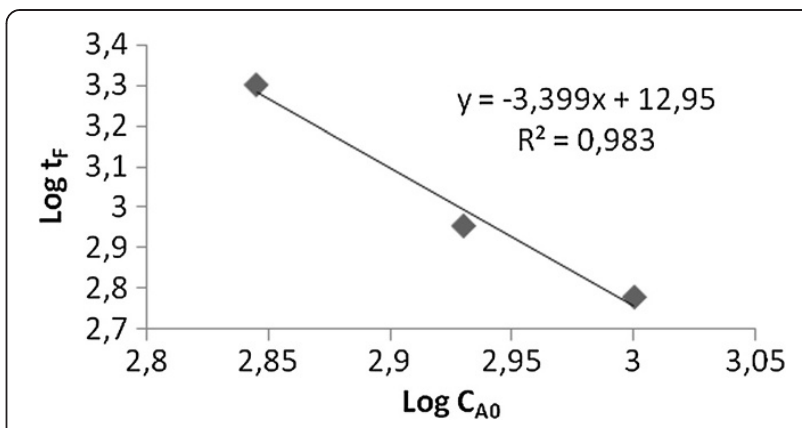

Figure 2 Lead adsorption reaction rate at $0^{\circ} \mathrm{C}$ (initial lead concentration $1005 \mathrm{mg} / \mathrm{L})\left(\mathrm{t}_{\mathrm{F}}(\mathrm{min}) ; \mathrm{C}_{\mathrm{AO}}(\mathrm{mg} / \mathrm{L})\right.$.

yield was obtained in diluted solutions $(10 \mathrm{mg} / \mathrm{L})$. When the initial lead concentration increased to $100 \mathrm{mg} / \mathrm{L}$, the yield decreased to 81 percent. Dai et al. [13] also observed that increase in initial lead concentration from 3 to $200 \mathrm{mg} / \mathrm{L}$ decreased the lead removal down to 70 percent. Also (Figure 1), the results of the study showed that this yield could also be achieved up to $500 \mathrm{mg} / \mathrm{L}$ of initial lead concentrations.

Adsorption time has little effect on lead removal. It was found that nearly 80-90 minute was enough to obtain highest yield in both dilute and concentrated solutions. The results obtained were in agreement with the work done by Dai [13] which reported that optimum time required to reach the equilibrium was $100 \mathrm{~min}$. Also Wang [14] reported that adsorption time has little effect on yield and that the adsorption required $90 \mathrm{~min}$.

Optimum conditions for the adsorption process were searched by numerical optimization section of the software by choosing different targets for initial lead ion concentration. As shown in Table 8, for dilute solutions (initial lead ion concentration up to $10 \mathrm{mg} / \mathrm{L}$ ), the best local maximum was found to be at adsorption time of 85-90 min, adsorption temperature of $50^{\circ} \mathrm{C}$, lead removal of nearly 84 percent, and desirability of 1.000 . High desirability shows that the estimated function may represent the experimental model and desired conditions. As the concentration increases, desirability and lead removal percentage were found to be decreasing (Table 8). Finally, 97 percent lead adsorption was achieved by using HDTMA-mordenite at the same optimum conditions of unmodified-mordenite; i.e. initial lead ion concentrations: $10-100 \mathrm{mg} / \mathrm{L}$. It can be concluded that,

Table 10 Thermodynamical constants of lead adsorption at different temperatures

\begin{tabular}{ccccc}
\hline $\mathbf{T}\left({ }^{\circ} \mathbf{C}\right)$ & $\mathbf{K c}^{\mathbf{0}}$ & $\Delta \mathbf{G}^{\mathbf{0}}(\mathbf{k J} / \mathbf{m o l})$ & $\Delta \mathbf{S}^{\mathbf{0}}$ & $\Delta \mathbf{H}^{\mathbf{0}}$ \\
\hline 20 & 0.791 & 571.44 & & \\
35 & 1.683 & -1333.70 & 15.91 & -4737 \\
50 & 3.55 & -3403.87 & & \\
\hline
\end{tabular}


modification of mordenite or adjustment of adsorption medium (lowering up to $\mathrm{pH} 3$ ) [13] produce nearly the same adsorption yield. But lowering the $\mathrm{pH}$ of the medium was useful for solutions containing $3 \mathrm{mg}$ lead $/ \mathrm{L}$ [13], whereas modification of mordenite was applicable up to $100 \mathrm{mg} / \mathrm{L}$ of lead solutions.

Fitting of adsorption data showed that (Table 9), Langmuir isotherm, thus monolayer adsorption, solely, was not suitable for the process. Equilibrium adsorption data were best represented by the Freundlich isotherm. Heterogeneous adsorption of lead on mordenite was also stated in the literature before [14]. The obtained value of $(1 / \mathrm{n})(0.1<1 / \mathrm{n}<1)$ demonstrated that favourable nature of both lead and the heterogeneity of the mordenite sites. The $1 / \mathrm{n}$ value of the present study was higher than those obtained $\left(0.537\right.$ at $30^{\circ} \mathrm{C} ; 0.555$ at $\left.40^{\circ} \mathrm{C}\right)$ [14] showing that higher adsorption intensity of the mordenite used. Negative Gibbs free energy (Table 10) indicated the spontaneous nature of adsorption at those temperatures. These results were well-matched with literature [14]. Also, negative $\Delta \mathrm{H}^{\circ}$ values showed the adsorption of lead ions was an exothermic process. A negative enthalpy values were also reported for the adsorption of lead ions onto wollastonite, bentonite and mordenite [14]. A positive $\Delta S^{\circ}$ value corresponded to an increase in both the randomness at the solid-solution interface and the degree of freedom of the adsorbed species. Adsorption reaction rate was found 4.4 at $0^{\circ} \mathrm{C}$ (Figure 2). In a different study, lead adsorption data $\left(\right.$ at $20-40^{\circ} \mathrm{C}$ ) onto a local mordenite were fitted well to several equations; pseudo-second order, parabolic diffusion and Elovich equations [14]. It seemed that the steps of adsorbate transport from the solution to the surface of mordenite; such as film diffusion, pore diffusion, surface diffusion and adsorption are strongly affected on temperature.

\section{Conclusions}

A Box-Behnken Design was conducted to study the effects of three adsorption variables, namely adsorption time, temperature and initial lead ion concentration on the adsorption yield of lead. Quadratic model and reduced cubic model were developed to correlate the variables to the response. Through the analysis of response surfaces, adsorption temperature and initial lead ion concentration were found to have significant effects on adsorption yield, whereas initial ion concentration showed that most significant. Process optimization was carried out and the experimental values were found to agree satisfactorily with the predicted values. Mordenite was shown to be a promising adsorbent for removal of lead from aqueous solutions. Further increase in the adsorption yield obtained at the optimum conditions was achieved with HDTMA-modification. Adsorption isotherm, adsorption kinetic and adsorption thermodynamics were studied. Equilibrium adsorption data were best represented by the Freundlich isotherm model. Thermodynamic calculations indicated that the adsorption was exothermic and spontaneous process.

\section{Competing interests}

The authors declared that they have no competing interests.

\section{Authors' contributions}

HT carried out part of the experimental studies. TK carried out part of the experiments and participated in the design of the study. SYY performed the statistical analysis, conceived of the study, and participated in its design and coordination and helped to prepare the manuscript. All authors read and approved the final manuscript.

\section{Acknowledgements}

The present research was funded under the code of 2635-YL-11 by Scientific Research Project Coordination Unit of Suleyman Demirel University (Turkey).

\section{Author details}

${ }^{1}$ Environmental Engineering Department, Suleyman Demirel University, Cunur, Isparta, Turkey. ${ }^{2}$ Chemical Engineering Department, Suleyman Demirel University, Cunur, Isparta, Turkey.

Received: 28 August 2012 Accepted: 6 October 2013

Published: 6 January 2014

\section{References}

1. Förstnet U, Wittmann GTW: Metal pollution in the aquatic environment Berlin: Springer Verlag; 1979.

2. Bahadir T, Bakan GL, Aitas $H$ : The investigation of lead removal by biosorption: an application at storage battery industry wastewaters. Enzyme Microb Technol 2007, 41:98-102.

3. Liu YG, Fan T, Zeng G, Li X, Tong Q, Ye F, Zhou M, Xu W, Huang Y: Removal of cadmium and zinc ions from aqueous solution by living Aspergillus niger. Trans Nonferrous Met Soc China 2006, 16:681-686.

4. Wang J, Chen C: Biosorption of heavy metals by Saccharomyces cerevisiae: a review. Biotechnol Adv 2006, 24:427-451.

5. Chen J, Wang L, Zhou S: Determination of lead biosorption properties by experimental and modelling simulation study. Chem Eng J 2007, 131:209-215.

6. Zhou P, Huang JC, Li AWF, Wie S: Heavy metal removal from wastewater in a fluidized bed reactor. Water Res 1999, 33:1918-1924.

7. Mousavi HZ, Hosseynifar A, Jahed V, Dehghani SAM: Removal of lead from aqueous solution using waste tire rubber ash as an adsorbent. Braz J Chem Eng 2010, 27:79-87.

8. Crini G: Non-conventional low-cost adsorbents for dye removal: a review. Bioresour Technol 2006, 97:1061-1085.

9. Wang S, Peng Y: Natural zeolites as effective adsorbents in water and wastewater treatment: review. Chem Eng J 2010, 156:11-24.

10. Godelitsas A, Armbruster T: HEU-type zeolites modified by transition elements and lead. Micropor Mesopor Mater 2003, 61:3-24.

11. Wang XS, Hu HQ, Sun C: Removal of $\mathrm{Cu}$ (II) ions from aqueous solutions using Na-mordenite. Sep Sci Technol 2007, 42:1215-1230.

12. Wang XS, Huang J, Hu HQ, Qin Y: Determination of kinetic and equilibrium parameters of the batch adsorption of $\mathrm{Ni}$ (II) from aqueous solutions by Na-mordenite. J Hazard Mater 2007, 142:468-476.

13. Dai S, Kato Y, Guang D, Amal R: Removal of lead (II) by mordenites. Dev Chem Eng Mineral Process 1998, 6:171-184

14. Wang $X S$, He L, Hu HQ, Wang J: Effect of temperature on the $\mathrm{Pb}$ (II) removal from single aqueous solutions by a locally natural mordenite: equilibrium and kinetic modelling. Separ Sci Technol 2008, 43:908-922.

15. Bas D, Boyaci IH: Modelling and optimisation I. Usability of response surface methodology. J Food Eng 2007, 78:836-845.

16. Preetha B, Viruthagiri T: Application of response surface methodology for the biosorption of cupper using Rhisopus arrhizus. J Hazard Mater 2007, 143:506-510.

17. Goksungur $Y$, Uren S, Guvenc U: Biosorption of cadmium and lead ions by ethanol treated waste baker's yeast biomass. Bioresource Technol 2005, 96:103-109. 
18. Aksu Z, Gonen F: Binary biosorption of phenol and chromium (VI) onto immobilized activated sludge in a packed bed: prediction of kinetic parameters and breakthrough curves. Sep Purif Technol 2006, 49:205-216.

19. Aksu Z: Determination of the equilibrium, kinetic and thermodynamic parameters of the batch biosorption of nickel (II) ions onto Chorella vulgaris. Process Biochem 2002, 38:89-99.

20. Benefield L, Judkins J, Weand B: Process chemistry for water and wastewater treatment. New York: Prentice Hall; 1982.

21. Levenspiel O: Chemical reaction engineering. United States of America: John Wiley and Sons; 1999.

22. Dakiky M, Khamis M, Manassra A, Mer'eb M: Selective adsorption of chromium (VI) in industrial wastewater using low-cost abundantly available adsorbents. Advances Environ Res 2002, 6:533-540.

23. Gok O, Ozcan AS, Ozcan A: Adsorption behaviour of a textile dye of Reactive Blue 19 from aqueous solutions onto modified bentonite. App/ Surf Sci 2010, 256:5439-5443.

doi:10.1186/2052-336X-12-5

Cite this article as: Turkyilmaz et al:: Optimization of lead adsorption of mordenite by response surface methodology: characterization and modification. Journal of Environmental Health Science \& Engineering 2014 12:5.

\section{Submit your next manuscript to BioMed Central and take full advantage of:}

- Convenient online submission

- Thorough peer review

- No space constraints or color figure charges

- Immediate publication on acceptance

- Inclusion in PubMed, CAS, Scopus and Google Scholar

- Research which is freely available for redistribution 